(a)

\title{
Impact of GADD34 on Apoptosis of Tonsillar Mononuclear Cells from IgA Nephropathy Patients by Regulating Eif2 $\alpha$ Phosphorylation
}

\author{
Xiaofei Peng ${ }^{a, b} \quad$ Tao Yang ${ }^{c}$ Liyu He ${ }^{b} \quad$ Xian Chen ${ }^{b}$ Yafeng Jiang ${ }^{b}$ Hao Zhang ${ }^{d}$ \\ Hong Liu ${ }^{b}$ Youming Peng ${ }^{b}$ \\ aDepartment of Rheumatology and Immunology, the Second Xiangya Hospital, Central South \\ University, Hunan, 'Department of Nephrology, the Second Xiangya Hospital, Central South University, \\ Hunan, 'Department of Otorhinolaryngology, the Second Xiangya Hospital, Central South University, \\ Hunan, dDepartment of Nephrology and Rheumatology, the Third Xiangya Hospital, Central South \\ University, Hunan, China
}

\section{Key Words}

IgA nephropathy • Tonsillar mononuclear cell • ER stress $•$ GADD34 • Cell apoptosis

\begin{abstract}
Background/Aims: Tonsillectomy may be an important method to achieve a long-term remission of IgAN, but patients' physical status may limit their access to this surgery. We proposed an encouraging solution through inhibiting GADD34 expression in order to promote tonsillar mononuclear cells (TMCs) apoptosis and reduce nephropathic IgA secretion. Methods: A total of $12 \operatorname{lgAN}$ and 9 non-lgAN patients were involved from March 2015 to May 2016. After TMCs were extracted by density gradient centrifugation and stimulated by inactivated hemolytic streptococcus, the mRNA and protein expression of GADD34, GRP78, CHOP, Bcl-2, $\mathrm{BCl}-\mathrm{XL}, \mathrm{AID}, \mathrm{l} \alpha-\mathrm{C} \alpha$, and cleaved caspase-3 were examined by fluorescent RT-PCR and Western blotting. Guanabenz treatment and siRNA interference were applied to downregulate GADD34 in tonsillar mononuclear cells from IgAN patients, and P-elF2 $\alpha$ expression was examined by Western Blotting. Cell apoptosis was evaluated by Annexin V FITC/PI flowcytometry, and IgA secretion in cultural supernatant was inspected by enzyme linked immunosorbent assay. Results: After stimulation, the expression of GADD34 was significantly increased in IgAN patients $(P<0.05)$. Cell apoptosis was mitigated and IgA secretion level was elevated $(P<0.05)$. To be noticed, CHOP expression had no significant difference between two groups. After guanabenz treatment and siRNA interference, a prolonged elevation of P-elF2 $\alpha$ expression was observed. Cell apoptosis was reinforced and IgA secretion level was decreased $(P<0.05)$. Conclusion: GADD34 may be a potential therapeutic target for IgAN treatment due to its effect on cell apoptosis.




\section{Introduction}

IgA nephropathy (IgAN) is the most common type of primary glomerular disease worldwide [1]. Recently a large amount of researches have revealed that tonsillitis, usually caused by $\alpha$-hemolytic streptococcus ( $\alpha$-HS), is closely associated with the pathogenesis of IgAN $[2,3]$. Tonsillar mononuclear cells (TMCs), primarily consist of lymphocytes, are mainly responsible for nephropathic IgA secretion in IgAN patients $[4,5]$. These nephropathic IgA can be reduced after tonsillectomy in most tonsillitis-associated IgAN patients [6]. A longterm remission and low risk of ESRD (end stage renal disease) could also be achieved after tonsillectomy in these patients $[2,6]$. Hence, tonsillectomy may be a feasible approach to treat IgAN. However, it should be noticed that tonsillectomy is an invasive treatment, and this surgery may be delayed or cancelled due to acute inflammation [7], poor coagulation, or acute nephritis. Therefore, an effective approach for IgAN treatment is urgently needed. Previous investigations have found that TMCs from IgAN patients exhibit lower apoptotic rates $[8,9]$, implying that we may reduce the nephropathic IgA level by regulating the cell death of TMCs.

Endoplasmic reticulum (ER) is the major structure responsible for protein synthesizing, folding, and transporting in cells [10]. When cell encounters an extracellular interference or a homeostatic imbalance, a series of adaptive reactions can be activated, called unfolded protein response (UPR) [11]. In order to alleviate the cell deterioration, these adaptive reactions in ER can activate pathways influencing cell apoptosis, redox equilibrium, energy production, and inflammation, etc [12]. If ER stress consistently exists, cells will suffer lethal damage [13]. Various factors can trigger ER stress, such as tunicamycin, palmitate, thapsigargin, and $\alpha$-HS [14].

There are three main signaling pathways involved in ER stress, including PERK, ATF6, and IRE1 $\alpha$ [15] (Fig. 1). The latter two pathways in ER stress can help maintain ER homeostasis [16], regulate protein folding and ERAD production $[17,18]$. Among these three pathways, PERK is the major one that regulates cell apoptosis. PERK is a trans-membranous protein

Fig. 1. Three main signaling pathways of ER stress. ER stress consists of three main signaling pathways, including PERK, ATF6, and IRE1 $\alpha$. PERK is a transmembranous protein, and it can influence protein folding, redox reaction, and amino acid metabolism, responsible for the cell apoptosis under ER stress. ATF6 is a membrane-bound transcriptional factor, and its activation can help maintain ER homeostasis. IRE1 can cleave XBP-1 and promote its expression, which can further regulate protein folding and ERAD production.

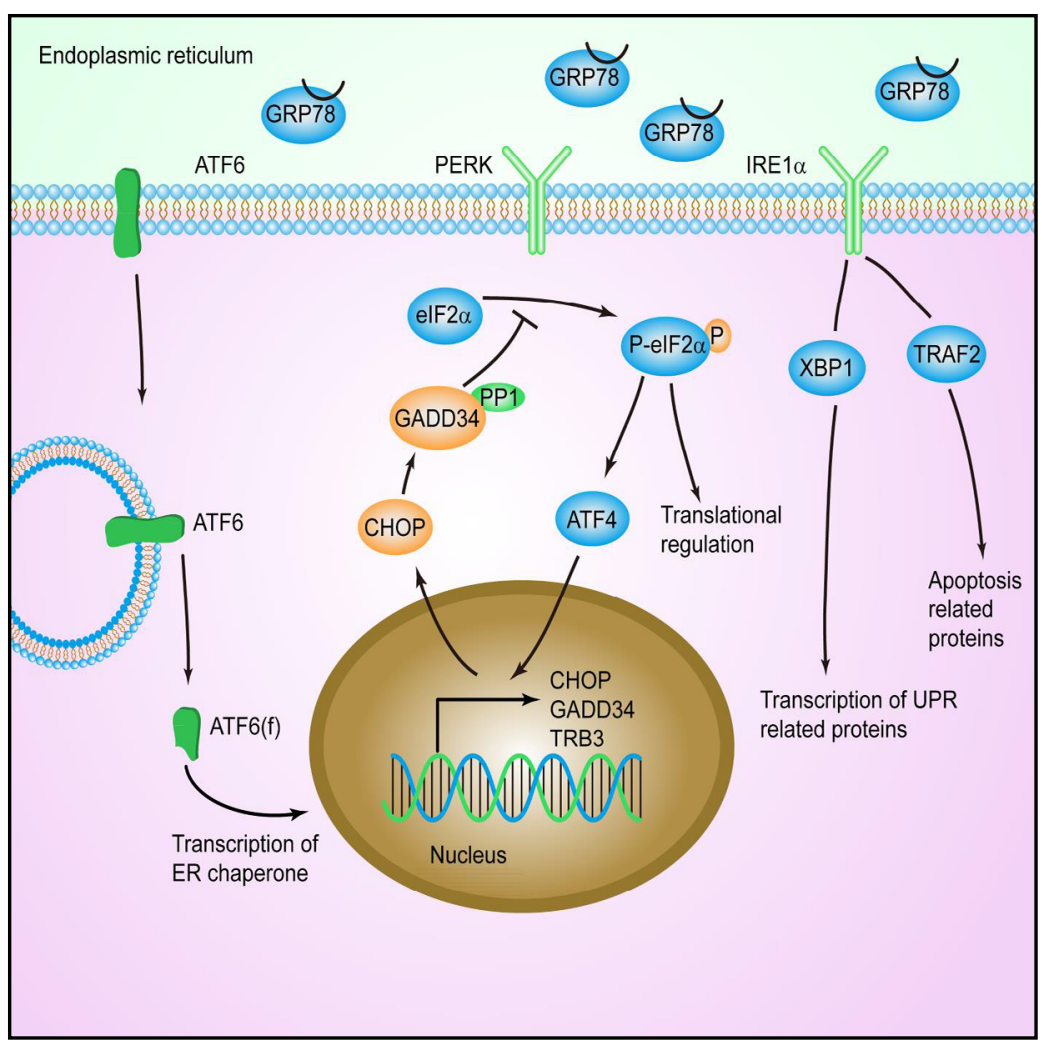


[19], and its luminal domain normally binds to GRP78, an ER associated protein [20]. When ER stress occurs, GRP78 can be released and PERK is now eligible to be activated [21]. After activation, PERK can further regulate cell apoptosis mediated by eIF2 $\alpha$. Phosphorylated eIF $2 \alpha$ prevents eIF $2 \alpha$ to become GTP-bound activated form (eIF2B) [22] and promotes ATF4 expression, further manipulating the expression of CHOP and GADD34 [23].

GADD34, along with its companion molecule PP1, can restrain eIF2 $\alpha$ phosphorylation and resume protein synthesis $[15,24]$. Some evidences have indicated that GADD34 may play a critical role in cell survival $[25,26]$. A high expression of GADD34 can dramatically decrease the susceptibility of Oca2-null melanocytes to thapsigargin [27]. It can also prevent the cell damage after TLR stimulation and inflammation [28]. Thus, GADD34 upregulation may function as a protective mechanism in cells under ER stress. In contrast, GADD34 downregulation can promote cell apoptosis. After GADD34 knockdown, eIF2 $\alpha$ phosphorylation, CHOP expression and apoptosis were increased in hepatoma cells [29]. Guanabenz, an $\alpha 2$ adrenergic receptor agonist, can bind with GADD34/PP1 and selectively interrupt the dephosphorylation of the $\alpha$ subunit in eIF2 $\alpha[30,31]$. Its treatment could significantly reduce cell viability in melanocytes after thapsigargin stimulation [27], suggesting that guanabenz can enhance cell apoptosis.

When UPR activation cannot effectively reduce the stress that cells suffer, internal and external apoptotic pathways can be activated. Cell apoptosis triggered by ER stress is primarily executed by mitochondria associated apoptotic pathway, and Bcl-2 family proteins are involved [32]. In UPR, CHOP is a pivotal protein in cell apoptosis [15]. A research has proved that CHOP-deficient myocardial cells of mice had reduced cell apoptosis [33]. CHOP can also directly inhibit Bcl-2 transcription and can also regulate the expression of GADD34 $[34,35]$. It is worth being noticed that CHOP has no effect on Bcl-XL expression [36]. Although cell apoptosis caused by ER stress is closely related with CHOP, some investigations revealed that cell apoptosis still exist in CHOP deficient cells [37], implying that other pro-apoptotic pathways may be involved except CHOP.

In our study, we stimulated TMCs from IgAN patients by using inactivated $\alpha$-HS in order to trigger ER stress. We investigated the expression of GADD34 in TMCs from IgAN patients and evaluated its impact on cell apoptosis, and further explored the effect of GADD34 downregulation on TMCs apoptosis and IgA secretion level through promoting eIF2 $\alpha$ phosphorylation. Eventually, an enlightening therapeutic target for IgAN treatment may be provided.

\section{Materials and Methods}

\section{Antibodies}

Antibodies for GRP78 and GADD34 were purchased from Proteintech Group (Wuhan, Hubei, China). Antibodies for P-eIF2 $\alpha$, CHOP, Bcl-XL, Bcl-2 and cleaved caspase-3 were purchased from Cell Signaling Technology (Denvers, MA, USA). Antibodies for $\beta$-actin were purchased from abcam. The secondary peroxidase-conjugated rabbit anti-human IgG $(\mathrm{H}+\mathrm{L})$ and peroxidase-conjugated mouse anti-human IgG $(\mathrm{H}+\mathrm{L})$ were purchased from Jackson ImmunoResearch Lab, Inc. (West Grove, PA, USA).

\section{Specimen collection}

Tonsillar mononuclear cells were extracted from the tonsil tissues of tonsillectomy patients in the Second Xiangya Hospital. IgA nephropathy patients were diagnosed according to their renal biopsy results. The patients were selected depending on the following criteria: 1. Age ranges from 16-50; . Anaphylactoid purpura, lupus nephritis, diabetic nephritis, hepatitis b-associated glomerulonephritis and other secondary nephritis are excluded; 3. Microscopic or gross hematuria is presented, with or without proteinuria. The tonsillitis patients involved in our research were hospitalized in the Second Xiangya Hospital from March 2015 to May 2016. The specimens from 14 IgAN patients and 12 non-IgAN patients were collected. This project was approved by the Human Ethics Review Committee of the Second Xiangya Hospital, Central South University. Consents of participation were obtained from all of the tonsillectomy patients. 


\section{Cellular Physiology Cell Physiol Biochem 2018;50:2203-2215 \begin{tabular}{l|l|l} 
and Biochemistry Published online: 10 November 2018 & $\begin{array}{l}\text { (c) } 2018 \text { The Author(s). Published by S. Karger AG, Basel } \\
\text { www.karger.com/cpb }\end{array}$ \\
\hline
\end{tabular}}

Peng et al.: Impact of GADD34 on TMCs Apoptosis

\section{Preparation of $\alpha$-hemolytic streptococcus suspension}

$\alpha$-hemolytic streptococcus ( $\alpha$-HS) was kindly provided by the Department of Clinical Laboratory at the Second Xiangya Hospital, Central South University. The $\alpha$-HS was inoculated onto blood agar medium and cultured under $37^{\circ} \mathrm{C}$ for $24-48$ hours. The bacteria were suspended in $0.9 \%$ sterile saline solution in a concentration of $1 \times 109 / \mathrm{ml}$ ( 5 Maxwell turbidity units) and were inactivated under constant temperature of $60^{\circ} \mathrm{C}$ for $30 \mathrm{~min}$. The bacteria suspension was stored in ultra-low temperature freezer.

\section{Cell Culture and drug treatment}

Tonsil specimens were obtained from patients undergoing tonsillectomy in the Second Xiangya Hospital, Central South University, Changsha, Hunan, China. Within 6 hours after surgical separation of the specimens, they were immersed into saline solution, cut into small pieces and then grinded in mortar in order to obtain tissue homogenate (saline was added). Fluids containing TMCs and other cell types were collected after the homogenate was pressed through 200-mesh sieve. TMCs from the collected tissue fluids were separated by density gradient centrifugation using human lymphocyte separation medium (TBD Science, Tianjin, China). After extracting the TMCs, the cells were cultured in RPMI 1640 supplemented with 10\% FBS (both from Gibco Life Sciences, Gaithersburg, MD, USA) and 1\% penicillin-streptomycin (Thermo Fisher Scientific, Hudson, NH, USA) under $5 \% \mathrm{CO} 2$ at $37^{\circ} \mathrm{C}(2 \times 106$ cells $/ \mathrm{ml})$. $\alpha$-HS were applied into the cultural medium with TMCs under different times or concentrations. Trypan blue stain assay was performed to evaluate the cell viability in guanabenz treatment group and guanabenz-free group. Three high power fields were observed and cell viability was recorded. The procedures above were repeated for three times. In drug treatment group, guanabenz (Sigma, St. Louis, MO, USA), was applied to the cell cultural medium comprised of merely RPMI 1640 plus 1\% penicillin-streptomycin. Guanabenz treatment was performed in 30 min prior to the application of $\alpha$-HS in the cultural medium.

\section{siRNA transfection}

GADD34-specific small interfering RNA (siRNA) oligos were synthesized by Ribobio (Guangzhou, China). TMCs from IgAN patients were transfected based on the instructions provided by TransIT-TKO ${ }$ (Mirus Bio, Madison, WI, USA). In short, TMCs were grown in a 12 -well plate with $2 \times 106$ cells/500ul medium of RPMI 1640 plus 10\% FBS each well. The cells were transfected by the mixture of $7 \mathrm{ul}$ transfection solution, 15.5ul siRNA, and 100ul Opti-MEM® I Reduced-Serum Medium (Gibco Life Sciences, Gaithersburg, MD, USA). Forty-eight hours after transfection, the cells were harvested, and proteins and RNAs were extracted for further processing.

\section{Western blotting}

Total proteins and phosphorylated proteins were extracted by RIPA supplemented with cOmplet Tablets, EDTA-free protease inhibitor and phosphatase inhibitor PhosphoStop (both from Roche, Indianapolis, IN, USA). Western blotting of 25-30ug protein samples was performed on SDS-PAGE electrophoresis and transfer membrane apparatus (Tanon, Shanghai, China) to transfer protein to PVDF membrane (Millipore, Billerica, MA, USA). The membrane then was blocked by 50\% BSA (Sigma, St. Louis, MO, USA) or 5\% skim milk solutions (BD Biosciences, San Diego, CA, USA) for 1 hour. After obtaining the results, the image were processed by Adobe Photoshop CS6 software, and the grey values of the bands were evaluated and analyzed by ImageJ $1.48 \mathrm{v}$ software.

\section{Immunohistochemical and fluorescent staining}

Sections were incubated with rabbit anti-human GADD34 antibody and a secondary goat anti-rabbit antibody consecutively. 3, 3'-diaminobenzidine tetrahydrochloride (DAB) solution was used to develop color, and the sections were then counterstained with hematoxylin. DAPI was used for nuclear fluorescent staining. The stained pictures were captured by Leika DMI 3000 B.

\section{Quantitative RT-PCR}

Total RNA was obtained using TRIzol (Invitrogen, Carlsbad, CA, USA) according to the manufacturer's protocol. RNA was reversely transcribed using PrimeScript RT reagent kit (Takara Bio, Japan). Quantitative PCR was accomplished by using SYBR Green (Takara Bio, Japan) and was performed on the ABI 7300 realtime PCR system (Applied Biosystems, USA). The primers sequences were provided in Table 1. 


\section{Cellular Physiology Cell Physiol Biochem 2018;50:2203-2215 \begin{tabular}{ll|l} 
DOl: 10.1159/000495061 & $\begin{array}{l}\text { O 2018 The Author(s). Published by S. Karger AG, Basel } \\
\text { www.karger.com/cpb }\end{array}$ \\
\cline { 2 - 3 } andine: 10 November 201
\end{tabular}

Table 1. Sequences of primers used in RT-PCR

\begin{tabular}{lccc}
\hline Genes & GenBank accession & $\begin{array}{c}\text { Forward primer } \\
\left(5^{\prime}-3^{\prime}\right)\end{array}$ & $\begin{array}{c}\text { Reverse primer } \\
\left(5^{\prime}-3^{\prime}\right)\end{array}$ \\
\hline GADD34 & NM_014330.3 & TCCTCTGGCAATCCCCCATA & $\begin{array}{c}\text { TGGTTTTCAGCCCCAGTGTT } \\
\text { GRP78 }\end{array}$ \\
NM_005347.4 & GAACGTCTGATTGGCGATGC & ACCACCTTGAACGGCAAGAA \\
ACTB & NC_000007.14 & CCTGGCACCCAGCACAAT & GGGCCGGACTCGTCATAC \\
CHOP & NM_001195053.1 & GCTCAGGAGGAAGAGGAGGA & TCCTGCTTGAGCCGTTCATT \\
Bcl-XL & NC_000020.11 & GACTGAATCGGATGGAGACC & GCAGTTCAAACTCGTCGCCT \\
AICDA & NM_020661.2 & TGGGGAAGCATTGCAAGGAA & AACGGCACAGGGATATGGTT \\
I $\alpha$-C $\alpha$ & -- & AAGGAGTGGACATTGCT & GATTCAGCAGCTCCACT \\
\hline
\end{tabular}

Flowcytometry

TMCs were processed according to instructions provided by FITC Annexin V detection kit (BD Pharmingen, USA). The flowcytometry was performed on BD FACSJazz ${ }^{\mathrm{TM}}$. The percentage of cells in quadrant 2 and 3 were added, generating the total percentage of apoptotic cells at both early and late apoptotic stage or apoptotic index. The images of the flowcytometry results were processed by Flowjo 7.6.1 software.

IgA secretion level detection

IgA secretion level was detected by Human IgA Platinum ELISA kit (eBioscience, USA) according to the manufacturer's protocol. The cultural supernatants were added into 96-well plate covered with IgA antibodies. The samples were diluted with $1 \times$ Assay Buffer and incubated by HRP-Conjugate solution for 1 hour on microplate shaker (400rpm) at room temperature. TMB Substrate Solution was used to terminate the reaction. The OD values were detected by Microplate Spectrophotometer (Molecular Devices, USA) under $450 \mathrm{~nm}$ wavelength.

\section{Statistical analysis}

Unpaired, two-tailed Student $t$ test was used to determine the statistical variances between the data sets; $p<0.05$ was considered statistically significant. The statistical significance was analyzed by SPSS Statistics 22 and GraphPad Prism 5.0 softwares. Linear regression methods and Pearson's correlation matrix were used to identify the parameters' correlation.

\section{Results}

Basic information of patients in two groups

The demographic and clinical information of the patients in both non-IgAN and IgAN groups are presented in Table 2. There were 14 IgAN patients, including 11 patients with focal segmental sclerosis. All of these patients had hematuria, and $78.6 \%$ had proteinuria. There were 12 non-IgAN patients involved, including 8 chronic tonsillitis (CT) patients and 4 CT patients with OSAHS (obstructive sleep apnea-hypopnea syndrome). None of these nonIgAN patients had proteinuria or hematuria. 
Table 2. Basic information of patients in non-IgAN and IgAN groups $( \pm S D)^{\# . ~ N S: n o ~ s i g n i f i c a n t ~ d i f f e r e n c e ; ~}$ NT: not tested; ${ }^{*} \mathrm{P}<0.05$. \#The age, gender composition, blood pressures, blood urea nitrogen, and serum uric acid had no significant difference between two groups. In contrast, the serum albumin in IgAN group was significantly decreased compared with non-IgAN group. Due to sustained blood pressure control and reasonable drug usa, no significant difference was observed in serum creatinine between two groups.

\begin{tabular}{lccc}
\hline Parameter & $\begin{array}{c}\text { Non-IgAN group } \\
(\mathrm{n}=12)\end{array}$ & $\begin{array}{c}\text { IgAN group } \\
(\mathrm{n}=14)\end{array}$ & P value \\
\hline Age (year) & $35 \pm 10.98$ & $26.79 \pm 5.65$ & NS \\
Gender (male/female) & $5 / 7$ & $6 / 8$ & NS \\
Systolic pressure $(\mathrm{mmHg})$ & $122.38 \pm 13.9$ & $125.67 \pm 15.3$ & NS \\
Diastolic pressure $(\mathrm{mmHg})$ & $81.25 \pm 13.19$ & $80.75 \pm 9.58$ & NS \\
Serum urea nitrogen $(\mathrm{mmol} / \mathrm{L})$ & $4.68 \pm 0.96$ & $4.93 \pm 1.68$ & NS \\
Serum creatinine $(\mu \mathrm{mol} / \mathrm{L})$ & $61.65 \pm 16.43$ & $75.05 \pm 22.88$ & NS \\
Serum uric acid $(\mu \mathrm{mol} / \mathrm{L})$ & $292.93 \pm 104.73$ & $341.38 \pm 87.65$ & NS \\
Serum albumin $(\mathrm{g} / \mathrm{L})$ & $38.98 \pm 3.43$ & $42.86 \pm 2.61 *$ & 0.019 \\
Hematuria $\left(10^{\wedge} 4 / \mathrm{ml}\right)$ & $13.44 \pm 18.87$ & - & NT \\
Proteinuria $(\mathrm{g} / \mathrm{d})$ & $1.1 \pm 0.77$ & - & NT \\
\hline
\end{tabular}

GADD34 expression and TMCs apoptosis in tonsils from non-IgAN and IgAN groups

The expressions of GADD34 and GRP78 in palatine tonsils from both groups were examined by immunohistochemical staining. In both groups, GADD34 and GRP78 were expressed primarily in germinal centers of palatine tonsils and scatteredly distributed in the surrounding diffused lymphoid tissue area. No significant difference of GRP78 expression was observed between the two groups. A higher GADD34 expression was detected in IgAN group compared with non-IgAN group (Fig. 2A).

The protein expressions of GRP78, GADD34, CHOP, Bcl-2, Bcl-XL, and cleaved caspase-3 were examined after 0,24 , and $48 \mathrm{~h} \alpha$-HS stimulation. The protein expressions of GADD34 after 24 and $48 \mathrm{~h}$ stimulation were notably increased in IgAN group. No significant difference for GRP78 expression was observed between two groups. It needs to be noticed that there was no noteworthy difference for CHOP expression between two groups, although the mean expression level was greater in IgAN gorup. Compared with non-IgAN group, the expression of cleaved caspase- 3 was dramatically reduced in IgAN group after 0 and $48 \mathrm{~h}$ stimulation. Solely in IgAN group, cleaved caspase-3 expression was evidently increased after $24 \mathrm{~h}$ stimulation compared with those after 0 and $48 \mathrm{~h}$ stimulation (Fig. 2B). After $24 \mathrm{hr}$ stimulation, the mRNA levels of GADD34 and Bcl-XL, as well as IgA class switching factors AID and $\mathrm{I} \alpha-\mathrm{C} \alpha$, were dramatically elevated in IgAN group. GRP78 mRNA level had no significant difference between two groups. The mean value of mRNA level for CHOP was augmented in IgAN group, but significant difference between two groups was not found (Fig. 2C).

The apoptotic index of TMCs from IgAN group was apparently declined after $24 \mathrm{~h}$ stimulation (Fig. 2D). Likewise, the percentage of TMCs at late apoptotic stage was dramatically decreased in IgAN group after $48 \mathrm{~h}$ stimulation (Fig. 2E). We also found that IgA 


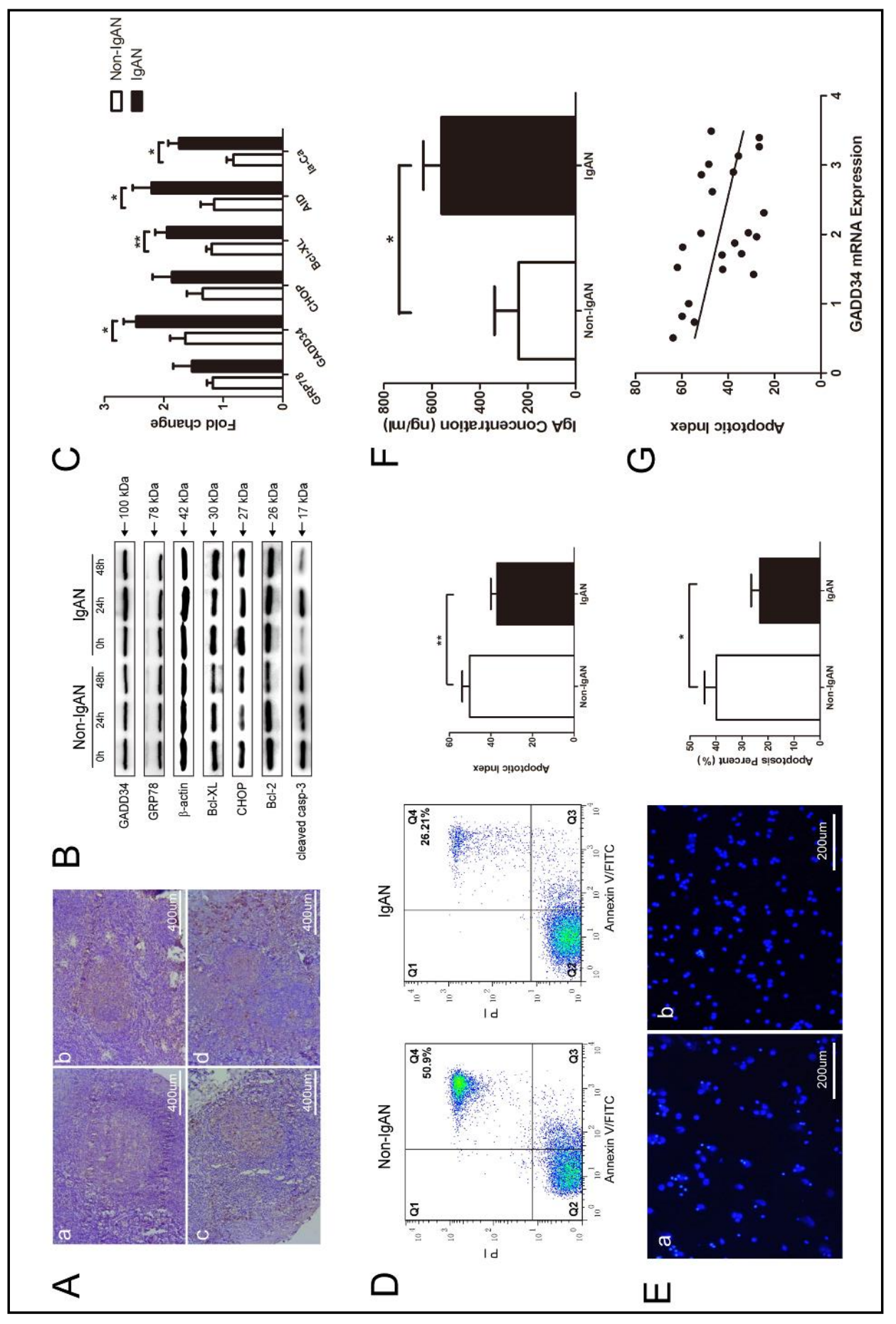

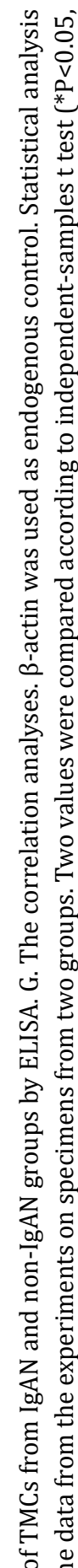

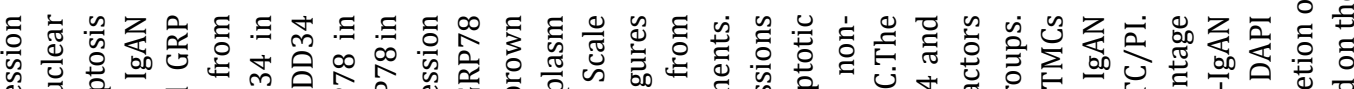

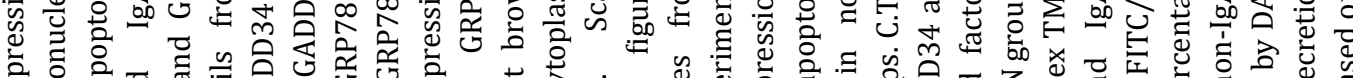

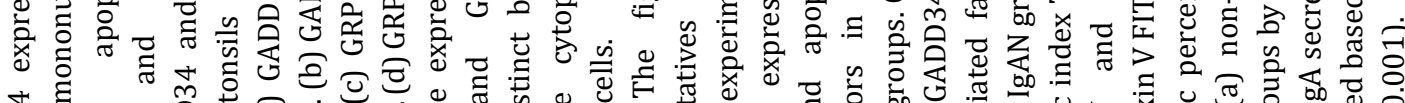

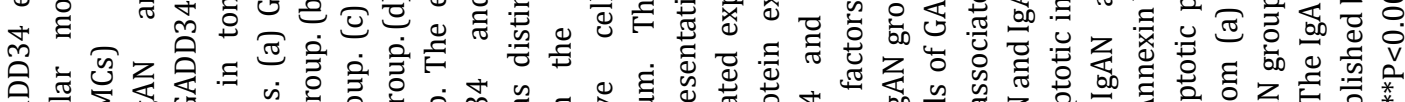

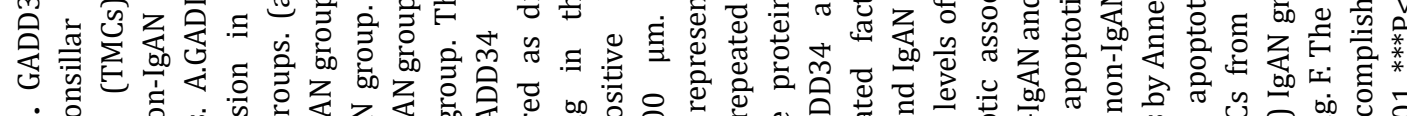
i

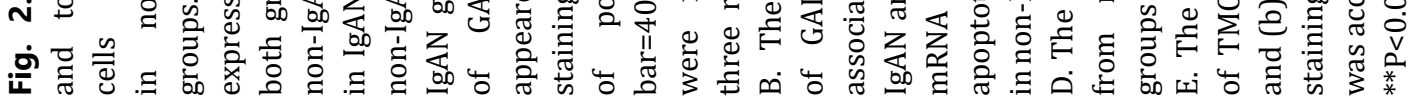
KARGER 


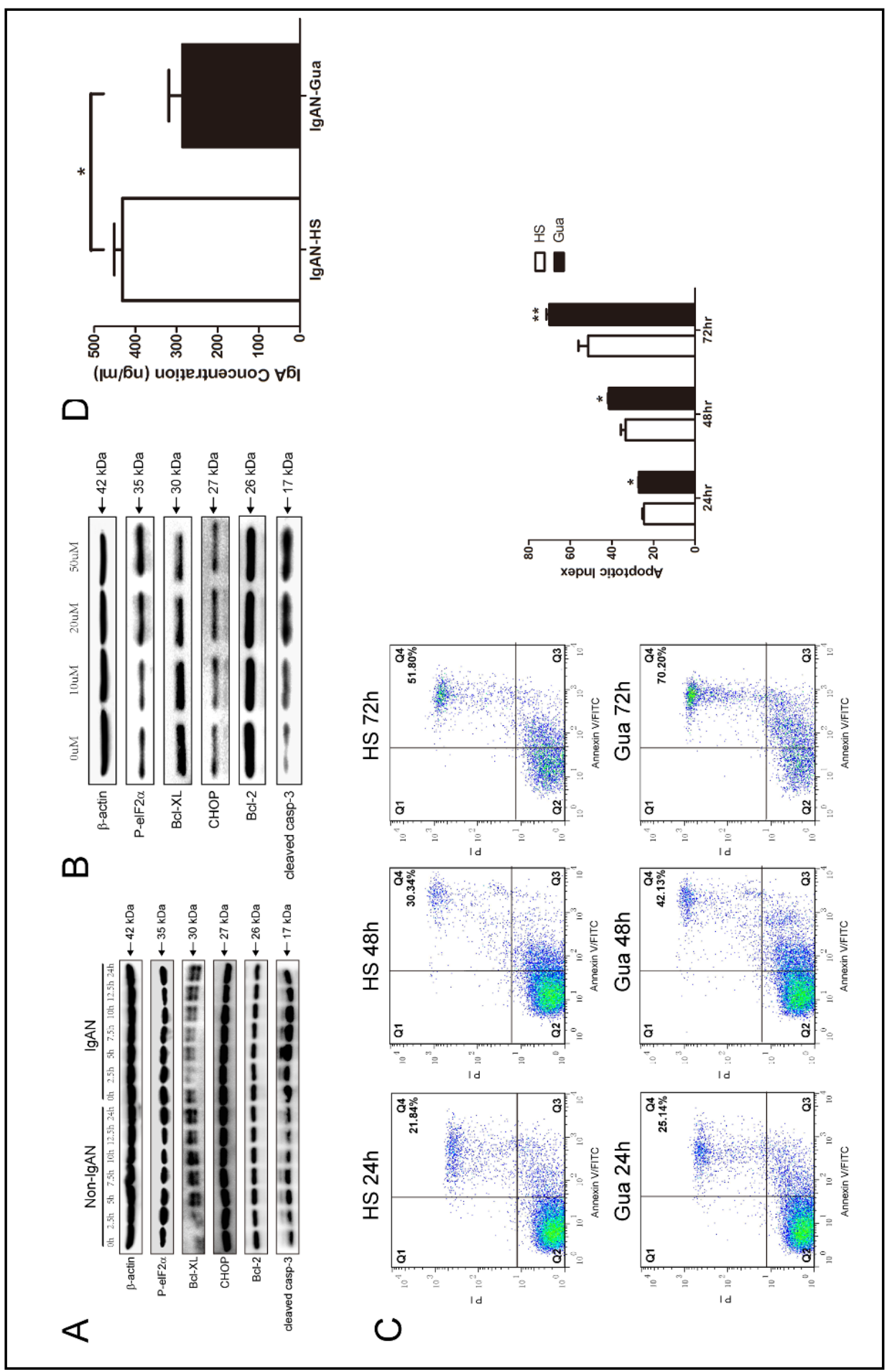

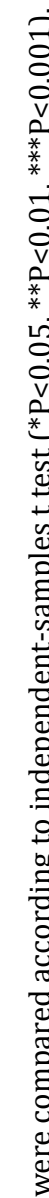

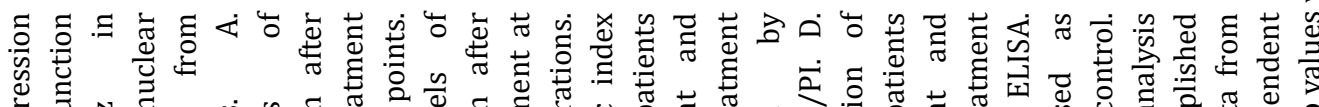

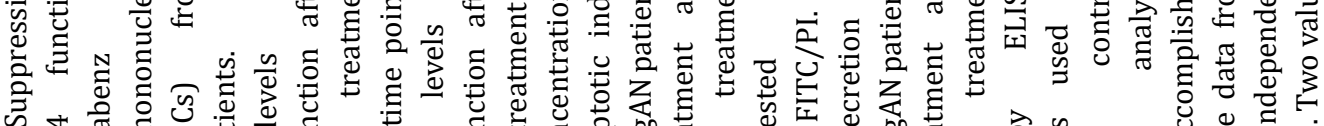

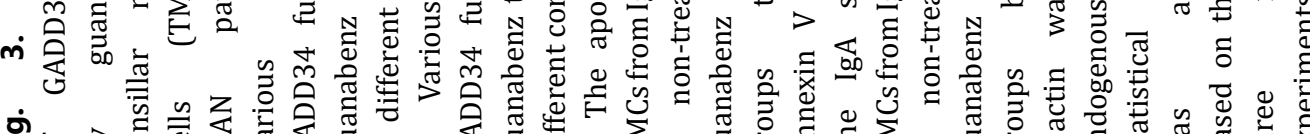

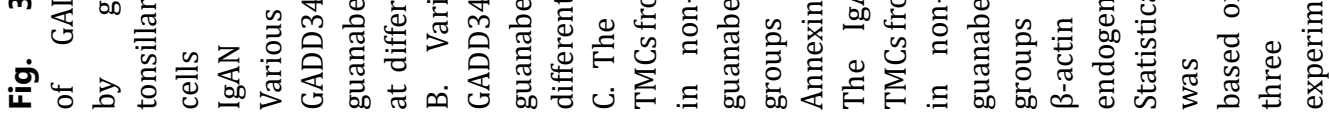
KARGER 


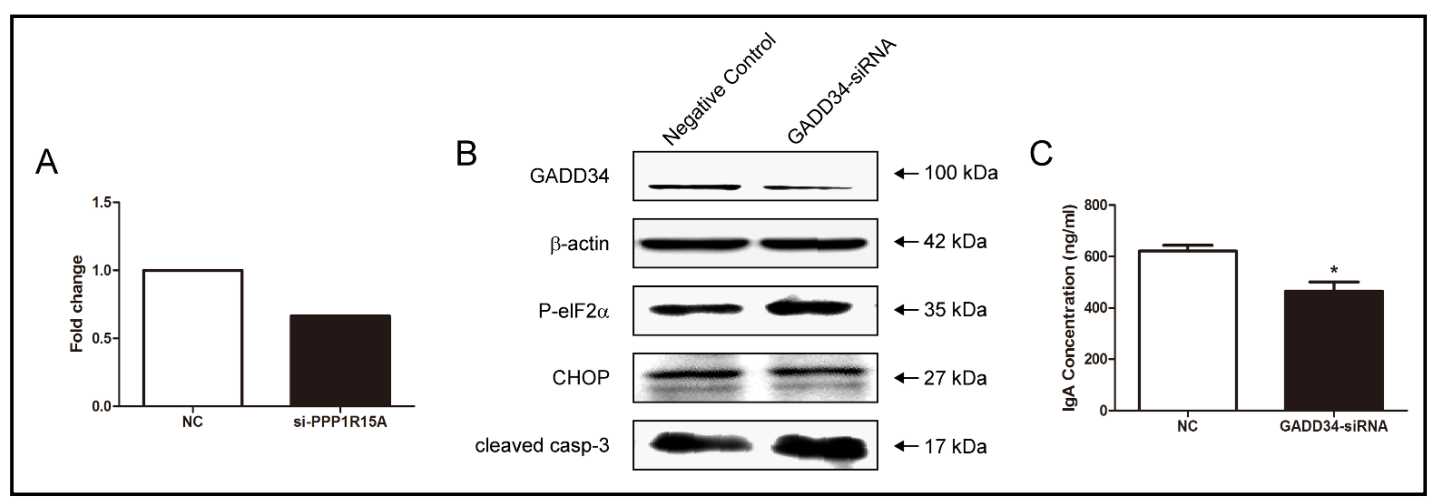

Fig. 4. Suppression of GADD34 function by guanabenz in tonsillar mononuclear cells (TMCs) from IgAN patients. A. GADD34 mRNA level after siRNA intervention. B. GADD34 and other apoptotic related proteins after siRNA intervention. C. The IgA secretion of TMCs from IgAN patients after siRNA intervention by ELISA. $\beta$-actin was used as endogenous control. Statistical analysis was accomplished based on the data from three independent experiments. Two values were compared according to independent-samples $\mathrm{t}$ test $\left({ }^{*} \mathrm{P}<0.05\right.$, $\left.{ }^{* *} \mathrm{P}<0.01,{ }^{* * *} \mathrm{P}<0.001\right)$.

secretion was enhanced in the cultural supernatant of TMCs from IgAN group (at cell density of $1 \times 10^{6} / \mathrm{ml}$ in complete culture medium) (Fig. 2F). According to these data, we presented that GADD34 mRNA level was negatively correlated with apoptotic index (Fig. 2G).

\section{Suppression of GADD34 function by applying guanabenz in TMCs from IgAN patients}

The cell viability was evaluated to examine the cytotoxicity of guanabenz. The cell viability was $90.84 \pm 3.88 \%$ in guanabenz-free group and was $89.56 \pm 3.99 \%$ in $20 \mathrm{uM}$ guanabenz treatment group (after $24 \mathrm{~h}$ culture). No statistically significant difference was detected ( $p$ value $>0.05$ ). After guanabenz treatment, the high expression of P-eIF2 $\alpha$ expression prolonged and could maintain even after $12.5 \mathrm{~h}$ application of guanabenz; in non-treatment group, P-eIF2 $\alpha$ expression reached its crest value after $2.5 \mathrm{~h}$ stimulation. The expression of cleaved caspase- 3 was also increased in guanabenz treatment group. Bcl-XL had a reduced expression after 5-10h application of guanabenz. We also found that after guanabenz treatment, the expressions of P-eIF $2 \alpha$ and cleaved caspase- 3 were increased and the expression of Bcl-XL was decreased, both in a dose-dependent manner. No significant differences of CHOP and Bcl-2 expressions were found between two groups (Fig. 3A\&B). The apoptotic indexes of TMCs were notably increased after 24,48 , and $72 \mathrm{~h}$ guanabenz treatment. The discrepancy of apoptotic index between these two groups was increased as time accumulation after guanabenz treatment (Fig. 3C). In addition, the IgA secretion was reduced after $48 \mathrm{~h}$ guanabenz treatment (at cell density of $1 \times 10^{6} / \mathrm{ml}$ in culture medium without FBS) (Fig. 3D).

\section{Inhibition of GADD34 expression by using siRNA in TMCs from IgAN patients}

After the intervention of GADD34-siRNA, the transfection efficiency was $52.5 \%$ according to fluorescent RT-PCR (Fig. 4A). The expression of P-eIF2 $\alpha$ was significantly increased after the gene silencing of GADD34, compared with negative control group. The expression of cleaved caspase- 3 was correspondingly increased. No significant change of CHOP expression was detected after siRNA interference (Fig. 4B). Furthermore, the IgA secretion level was markedly declined after GADD34 downregulation (at cell density of $4 \times 10^{6} / \mathrm{ml}$ in culture medium without antibiotics) (Fig. 4C). 


\section{Cellular Physiology Cell Physiol Biochem 2018;50:2203-2215

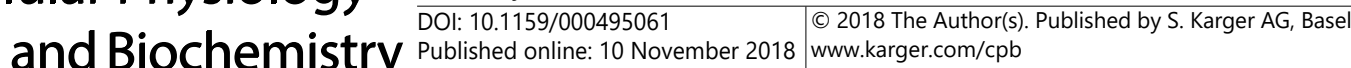 \\ Peng et al.: Impact of GADD34 on TMCs Apoptosis}

\section{Discussion}

IgA nephropathy is a chronically progressive disease. Approximately $50 \%$ of the IgAN patients will develop into ESRD [38]. Recent research has indicated that the nephropathic IgA antibodies were probably secreted from palatine tonsils [39]. After $\alpha$-HS infection, TMCs can undergo ER stress and the following responses could help with the recovery of homeostasis. Series of pro-survival and pro-apoptotic pathways are involved in UPR [11]. Under a prolonged ER stress, cells would inevitably step into death [40]. In our research, we used inactivated $\alpha$-HS to stimulate TMCs and trigger ER stress, inducing GADD34 expression by activating UPR.

The function of GADD34 on cell apoptosis has been controversial based on recent researches [41]. Inaba et al. revealed that eIF2 $\alpha$ phosphorylation could prevent the regeneration of hepatic tissue by reducing cell proliferation and promoting cell death. An enhancement of GADD34 expression could inhibit eIF2 $\alpha$ phosphorylation and reduce hepatic cells apoptosis, dramatically improve the tissue regeneration [42]. On the other hand, GADD34 deficiency could lead to an increase of apoptotic rate of macrophages, strengthen the activation of mTOR-S6K signaling pathway, and reduce LC3-II and autophagosome formation [40]. In our research, we found that the TMCs from IgAN group had an increased GADD34 and a declined apoptosis, suggesting that the high expression of GADD34 was associated with cell survival. GADD34 expression might be a reactive protection mechanism after stimulation. Additionally, GRP78 expression can reflect the degree of cellular stimulation [43]. According to our result, GRP78 expression was similar between non-IgAN and IgAN groups, denoting that the inflammation and stimulation levels were nearly identical in these two groups.

Previous researches illustrated that CHOP was closely associated with cell apoptosis. In neurocytes, CHOP-Wnt signaling pathway participated in the cell apoptosis triggered by tunicamycin-induced ER stress, and CHOP gene silencing could inhibit the damage caused by ER stress $[24,44]$. Research also found that after inducing ATF 4 and CHOP expression by adenovirus stimulation, cell apoptosis were enhanced, but a sole rise in CHOP expression would not impact cell apoptosis, implying that signaling other than CHOP might be involved [45]. In our investigation, we found that there was no significant difference for CHOP expression between non-IgAN and IgAN groups. CHOP expression was not paralleled with TMCs apoptotic level, suggesting that CHOP expression may not directly result in cell death. Furthermore, CHOP can regulate GADD34 expression [46], so the moderate expression of CHOP in TMCs from IgAN group may be associated with GADD34 maintenance.

The cell apoptosis caused by ER stress is mainly mediated by Bcl-2 family proteins. Bcl$\mathrm{XL}$ is an anti-apoptotic protein in Bcl-2 family proteins [47]. Research demonstrated that Bcl$\mathrm{XL}$ could activate NF- $\kappa \mathrm{B}$ and promote cell survival [48]. Our investigation also revealed that Bcl-XL expression was higher in IgAN group, verifying that the cell apoptosis caused by ER stress was mediated by Bcl- 2 family proteins. Unlike Bcl-XL, Bcl-2 expression is dependent on CHOP expression, and no significant increase of Bcl-2 expression in IgAN group was observed. Cleaved caspase-3 can directly reflect the apoptosis level [49]. Han et al. found that cleaved caspase- 3 could be detected after tunicamycin stimulation in MEFs, and this happened after the increase of ATF4 and CHOP expression [45]. In our research, we revealed that the cleaved caspase- 3 expression after $24 \mathrm{~h}$ stimulation was increased compared with 0 and $48 \mathrm{~h}$, suggesting that ER stress may briefly induce cell apoptosis pathway. We may also conclude that ER stress may promote the expression of both GADD34 and pro-apoptotic proteins at the beginning of the stimulation, but the high expression of GADD34 may then downregulate cell apoptosis through a negative feedback loop. As a result, a consequential reduction in IgA secretion was followed.

Guanabenz is a selective inhibitor for preventing GADD34-PP1 formation [30]. In melanocytes, eIF $2 \alpha$ could be rapidly dephosphorylated by GADD34 function after thapsigargin stimulation. The additional use of guanabenz could prevent eIF $2 \alpha$ dephosphorylation and thus restore the phosphorylation of eIF2 $\alpha$ and the pro-apoptotic pathway [27]. We proved 


\section{Cellular Physiology Cell Physiol Biochem 2018;50:2203-2215

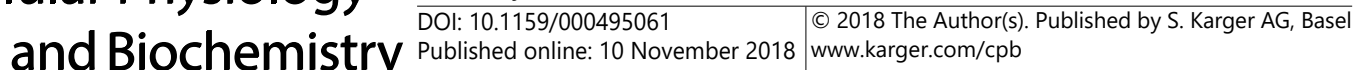 \\ Peng et al.: Impact of GADD34 on TMCs Apoptosis}

that P-eIF2 $\alpha$ expression and cell apoptosis was enhanced in guanabenz treatment group. Similarly, GADD34 gene silencing could also reinforce the eIF $2 \alpha$ phosphorylation and increase cell apoptosis [29]. After using shRNA to terminate GADD34 transcription, the cell apoptosis could be increased after LPS stimulation [40]. Another research also revealed that after the gene silencing of GADD34, IRE1 $\alpha$, or GRP78 in AML cells, cell apoptosis was prominently increased [50]. We applied siRNA to interfere GADD34 transcription. Then we found that P-eIF2 $\alpha$ and cell apoptosis was increased, demonstrating that GADD34 might protect TMCs from cell death caused by $\alpha$-HS stimulation.

\section{Conclusion}

In a conclusion, GADD34 may reduce cell apoptosis and secretory IgA level through inhibiting eIF2 $\alpha$ phosphorylation. Thus, GADD34 may be a potential therapeutic target for IgAN treatment. After GADD34 downregulation by guanabenz treatment or siRNA interference, a reduced secretory IgA level was accompanied by an increase in cell apoptosis. The lowered IgA level may further reduce IgA deposition in kidney and alleviate renal damage. This process still needes to be further investigated on animal models, such as the local use of GADD34 blocker in MALT (mucosa-associated lymphoid tissue) of IgAN-prone rats.

\section{Acknowledgements}

This work was supported by research grants from the National Natural Science Foundation of China (81870500, 81770714 and 81470947). It was also supported by research grant (2017JJ2002) from the Natural Science Foundation of Hunan province, and a research grant from Health and Family Planning Commission of Hunan Province (20180922), the Changde Municipal Science and Technology Bureau(2016KZ34).

\section{Disclosure Statement}

The authors declare that there are no conflicts of interest.

\section{References}

1 Suzuki Y, Suzuki H, Nakata J, Sato D, Kajiyama T, Watanabe T, Tomino Y: Pathological role of tonsillar B cells in IgA nephropathy. Clin Dev Immunol 2011;2011:639074.

2 Hoshino J, Fujii T, Usui J, Fujii T, Ohashi K, Takaichi K, Suzuki S, Ubara Y, Yamagata K: Renal outcome after tonsillectomy plus corticosteroid pulse therapy in patients with immunoglobulin A nephropathy: results of a multicenter cohort study. Clin Exp Nephrol 2015;10.1007/s10157-015-1194-z.

-3 Chen X, Liu H, Peng Y, He L, Zhang Y, Xie Y, Peng X, Liu C, Liu F: Expression and correlation analysis of IL-4, IF- $\gamma$ and Fc $\alpha$ RI in tonsillar mononuclear cells in patients with IgA nephropathy. Cell Immunol 2014;289:7075 .

4 Tang Y, Peng Y, Yang S, Liu H, Wu G, Liu F: Effect of tonsillar mononuclear cell supernatants in patients with IgA nephropathy on renal tubular epithelial cells. Inflamm Res 2013;62:45-52.

5 He L, Peng X, Wang J, Tang C, Zhou X, Liu H, Liu F, Sun L, Peng Y: Synthetic Double-Stranded RNA Poly(I:C) Aggravates IgA Nephropathy by Triggering IgA Class Switching Recombination through the TLR3-BAFF Axis. Am J Nephrol 2015;42:185-197.

-6 Yang D, He L; Peng X, Liu H, Peng Y, Yuan S, Liu Y, Chen X, Liu F, Liu C: The efficacy of tonsillectomy on clinical remission and relapse in patients with IgA nephropathy: a randomized controlled trial. Ren Fail 2016;38:242-248. 


\section{Cellular Physiology Cell Physiol Biochem 2018;50:2203-2215 and Biochemistry \begin{tabular}{l|l} 
DOI: 10.1159/000495061 2018 The Author(s). Published by S. Karger AG, Basel \\
Publion 2018
\end{tabular}

7 Windfuhr JP, Toepfner N, Steffen G, Waldfahrer F, Berner R: Clinical practice guideline: tonsillitis II. Surgical management. Eur Arch Otorhinolaryngol 2016;10.1007/s00405-016-3904-x.

8 Kodama S, Suzuki M, Arita M, Mogi G: Increase in tonsillar germinal centre B-1 cell numbers in IgA nephropathy (IgAN) patients and reduced susceptibility to Fas-mediated apoptosis. Clin Exp Immunol 2001;123:301-308.

-9 Yan W, Peng Y, Liu C, Ye M, Chen X, Peng X, He L, Wang J, Liu H, Liu F, Zhang G: Efficacy of triptolide on the apoptosis of tonsillar mononuclear cells from patients with IgA nephropathy. Ren Fail 2016;38:109-116.

$\checkmark 10$ Scheper W, Hoozemans JJ: The unfolded protein response in neurodegenerative diseases: a neuropathological perspective. Acta Neuropathol 2015;130:315-331.

11 Hetz C: The unfolded protein response: controlling cell fate decisions under ER stress and beyond. Nat Rev Mol Cell Biol 2012;13:89-102.

12 Walter P, Ron D: The unfolded protein response: from stress pathway to homeostatic regulation. Science 2011;334:1081-1086.

13 Tabas I, Ron D: Integrating the mechanisms of apoptosis induced by endoplasmic reticulum stress. Nat Cell Biol 2011;13:184-190.

14 Baruch M, Hertzog BB, Ravins M, Anand A, Cheng CY, Biswas D, Tirosh B, Hanski E: Induction of endoplasmic reticulum stress and unfolded protein response constitutes a pathogenic strategy of group A streptococcus. Front Cell Infect Microbiol 2014;4:105.

15 Sano R, Reed JC: ER stress-induced cell death mechanisms. Biochim Biophys Acta 2013;1833:3460-3470.

$\checkmark 16$ Asada R, Kanemoto S, Kondo S, Saito A, Imaizumi K: The signalling from endoplasmic reticulum-resident bZIP transcription factors involved in diverse cellular physiology. J Biochem 2011;149:507-518.

17 Calfon M, Zeng H, Urano F, Till JH, Hubbard SR, Harding HP, Clark SG, Ron D: IRE1 couples endoplasmic reticulum load to secretory capacity by processing the XBP-1 mRNA. Nature 2002;415:92-96.

-18 Acosta-Alvear D, Zhou Y, Blais A, Tsikitis M, Lents NH, Arias C, Lennon CJ, Kluger Y, Dynlacht BD: XBP1 controls diverse cell type- and condition-specific transcriptional regulatory networks. Mol Cell 2007;27:5366.

19 Harding HP, Zhang Y, Zeng H, Novoa I, Lu PD, Calfon M, Sadri N, Yun C, Popko B, Paules R, Stojdl DF, Bell JC, Hettmann T, Leiden JM, Ron D: An integrated stress response regulates amino acid metabolism and resistance to oxidative stress. Mol Cell 2003;11:619-633.

20 Kozutsumi Y, Segal M, Normington K, Gething MJ, Sambrook J: The presence of malfolded proteins in the endoplasmic reticulum signals the induction of glucose-regulated proteins. Nature 1988;332:462-464.

21 Gardner BM, Walter P: Unfolded proteins are Ire1-activating ligands that directly induce the unfolded protein response. Science 2011;333:1891-1894.

22 Kashiwagi K, Takahashi M, Nishimoto M, Hiyama TB, Higo T, Umehara T, Sakamoto K, Ito T, Yokoyama S: Crystal structure of eukaryotic translation initiation factor 2B. Nature 2016;531:122-125.

23 Rutkowski DT, Kaufman RJ: A trip to the ER: coping with stress. Trends Cell Biol 2004;14:20-28.

24 Marciniak SJ, Yun CY, Oyadomari S, Novoa I, Zhang Y, Jungreis R, Nagata K, Harding HP, Ron D: CHOP induces death by promoting protein synthesis and oxidation in the stressed endoplasmic reticulum. Genes Dev 2004;18:3066-3077.

25 Mukai R, Ohshima T: HTLV-1 HBZ positively regulates the mTOR signaling pathway via inhibition of GADD34 activity in the cytoplasm. Oncogene 2014;33:2317-2328.

-26 Liu L, Nishio N, Ito S, Tanaka Y, Isobe K: Negative regulation of GADD34 on myofibroblasts during cutaneous wound healing. Biomed Res Int 2014;2014:137049.

27 Cheng T, Orlow SJ, Manga P: Loss of Oca2 disrupts the unfolded protein response and increases resistance to endoplasmic reticulum stress in melanocytes. Pigment Cell Melanoma Res 2013;26:826-834.

28 Gu M, Ouyang C, Lin W, Zhang T, Cao X, Xia Z, Wang X: Phosphatase holoenzyme PP1/GADD34 negatively regulates TLR response by inhibiting TAK1 serine 412 phosphorylation. J Immunol 2014;192:2846-2856.

29 Teng Y, Gao M, Wang J, Kong Q, Hua H, Luo T, Jiang Y: Inhibition of eIF2alpha dephosphorylation enhances TRAIL-induced apoptosis in hepatoma cells. Cell Death Dis 2014;5:e1060.

-30 Vieira FG, Ping Q, Moreno AJ, Kidd JD, Thompson K, Jiang B, Lincecum JM, Wang MZ, De Zutter GS, Tassinari VR, Levine B, Hatzipetros T, Gill A, Perrin S: Guanabenz Treatment Accelerates Disease in a Mutant SOD1 Mouse Model of ALS. PLoS One 2015;10:e0135570.

-31 Tsaytler P, Harding HP, Ron D, Bertolotti A: Selective inhibition of a regulatory subunit of protein phosphatase 1 restores proteostasis. Science 2011;332:91-94. 


\section{Cellular Physiology Cell Physiol Biochem 2018;50:2203-2215 and Biochemistry \begin{tabular}{l|l} 
DOI: 10.1159/000495061 2018 The Author(s). Published by S. Karger AG, Basel \\
Published
\end{tabular}

-32 Shore GC, Papa FR, Oakes SA: Signaling cell death from the endoplasmic reticulum stress response. Curr Opin Cell Biol 2011;23:143-149.

-33 Fu HY, Okada K, Liao Y, Tsukamoto O, Isomura T, Asai M, Sawada T, Okuda K, Asano Y, Sanada S, Asanuma H, Asakura M, Takashima S, Komuro I, Kitakaze M, Minamino T: Ablation of C/EBP homologous protein attenuates endoplasmic reticulum-mediated apoptosis and cardiac dysfunction induced by pressure overload. Circulation 2010;122:361-369.

34 McCullough KD, Martindale JL, Klotz LO, Aw TY, Holbrook NJ: Gadd153 sensitizes cells to endoplasmic reticulum stress by down-regulating Bcl2 and perturbing the cellular redox state. Mol Cell Biol 2001;21:1249-1259.

-35 Puthalakath H, O’Reilly LA, Gunn P, Lee L, Kelly PN, Huntington ND, Hughes PD, Michalak EM, McKimmBreschkin J, Motoyama N, Gotoh T, Akira S, Bouillet P, Strasser A: ER stress triggers apoptosis by activating BH3-only protein Bim. Cell 2007;129:1337-1349.

-36 Jiang CC, Wroblewski D, Yang F, Hersey P, Zhang XD: Human melanoma cells under endoplasmic reticulum stress are more susceptible to apoptosis induced by the BH3 mimetic obatoclax. Neoplasia 2009;11:945955.

37 Urra H, Dufey E, Lisbona F, Rojas-Rivera D, Hetz C: When ER stress reaches a dead end. Biochim Biophys Acta 2013;1833:3507-3517.

-38 Nasri H, Mubarak M: Extracapillary proliferation in IgA nephropathy; recent findings and new ideas. J Nephropathol 2015;4:1-5.

39 Meng HX, Li HN, Geng JS, Ohe R, Yu XY, E XQ, Ye F, Yang SR, Kato T, Zhang L, Ishida A, Ohta N, Jin XM, Kakehata S, Geng JS, Yamakawa M: Decreased expression of follicular dendritic cell-secreted protein correlates with increased immunoglobulin A production in the tonsils of individuals with immunoglobulin A nephropathy. Transl Res 2015;166:281-291.

$>40$ Ito S, Tanaka Y, Oshino R, Aiba K, Thanasegaran S, Nishio N, Isobe K: GADD34 inhibits activation-induced apoptosis of macrophages through enhancement of autophagy. Sci Rep 2015;5:8327.

41 Wu H, Wei L, Fan F, Ji S, Zhang S, Geng J, Hong L, Fan X, Chen Q, Tian J, Jiang M, Sun X, Jin C, Yin ZY, Liu Q Zhang J, Qin F, Lin KH, Yu JS, Deng X, Wang HR, Zhao B, Johnson RL, Chen L, Zhou D: Integration of Hippo signalling and the unfolded protein response to restrain liver overgrowth and tumorigenesis. Nat Commun $2015 ; 6: 6239$.

42 Inaba Y, Furutani T, Kimura K, Watanabe H, Haga S, Kido Y, Matsumoto M, Yamamoto Y, Harada K, Kaneko S, Oyadomari S, Ozaki M, Kasuga M, Inoue H: Growth arrest and DNA damage-inducible 34 regulates liver regeneration in hepatic steatosis in mice. Hepatology 2015;61:1343-1356.

43 Yin J, Wang Y, Gu L, Fan N, Ma Y, Peng Y: Palmitate induces endoplasmic reticulum stress and autophagy in mature adipocytes: implications for apoptosis and inflammation. Int J Mol Med 2015;35:932-940.

44 Song Q, Gou WL, Zhang R: FAM3A attenuates ER stress-induced mitochondrial dysfunction and apoptosis via CHOP-Wnt pathway. Neurochem Int 2016;10.1016/j.neuint.2016.02.010.

45 Han J, Back SH, Hur J, Lin YH, Gildersleeve R, Shan J, Yuan CL, Krokowski D, Wang S, Hatzoglou M, Kilberg MS, Sartor MA, Kaufman RJ: ER-stress-induced transcriptional regulation increases protein synthesis leading to cell death. Nat Cell Biol 2013;15:481-490.

-46 Campos G, Schmidt-Heck W, Ghallab A, Rochlitz K, Putter L, Medinas DB, Hetz C, Widera A, Cadenas C, Begher-Tibbe B, Reif R, Gunther G, Sachinidis A, Hengstler JG, Godoy P: The transcription factor CHOP, a central component of the transcriptional regulatory network induced upon CCl4 intoxication in mouse liver, is not a critical mediator of hepatotoxicity. Arch Toxicol 2014;88:1267-1280.

47 Szegezdi E, Macdonald DC, Ni Chonghaile T, Gupta S, Samali A: Bcl-2 family on guard at the ER. Am J Physiol Cell Physiol 2009;296:C941-953.

48 Barroso-Gonzalez J, Auclair S, Luan S, Thomas L, Atkins KM, Aslan JE, Thomas LL, Zhao J, Zhao Y, Thomas G: PACS-2 mediates the ATM and NF-kappaB-dependent induction of anti-apoptotic Bcl-xL in response to DNA damage. Cell Death Differ 2016;10.1038/cdd.2016.23.

49 Maes M, Vanhaecke T, Cogliati B, Yanguas SC, Willebrords J, Rogiers V, Vinken M: Measurement of Apoptotic and Necrotic Cell Death in Primary Hepatocyte Cultures. Methods Mol Biol 2015;1250:349-361.

-50 Rahmani M, Mayo M, Dash R, Sokhi UK, Dmitriev IP, Sarkar D, Dent P, Curiel DT, Fisher PB, Grant S: Melanoma differentiation associated gene-7/interleukin-24 potently induces apoptosis in human myeloid leukemia cells through a process regulated by endoplasmic reticulum stress. Mol Pharmacol 2010;78:1096-1104. 